http://dx.doi.org/10.21707/gs.v10.n01a03

\title{
Notas y perspectivas sobre la Ciudad Rural Sustentable “Santiago El Pinar”. Una experiencia en Chiapas, Sureste de México
}

\author{
Eduardo Gómez Gómez \& Guillermo Montoya Gómez ${ }^{2}$
}

\begin{abstract}
${ }^{1}$ Licenciado en Economía por la Facultad de Ciencias Sociales-Universidad Autónoma de Chiapas, México E-mail: capi98@hotmail.com
${ }^{2}$ Doutor em Economia Agricola - Universidad Nacional Autónoma de México (UNAM) Profesor de la Universidad Autónoma de Chiapas (UNACH). Profesor Titular -Investigador de El Colegio
\end{abstract} de la Frontera Sur (ECOSUR)-San Cristóbal de Las Casas. Membro del Sistema Nacional de Investigadores (SIN) Nivel 1s. E-mail: gmontoya@ecosur.mx

Recebido em 20 de março de 2016. Aceito em 31 de maio de 2016. Publicado em 30 de junho de 2016.

\begin{abstract}
Resumen - Este artículo trata desde la perspectiva crítica los vaivenes de una política gubernamental de desarrollo del Estado mexicano encabezado entonces por el Presidente de la República Felipe Calderón Hinojosa durante el sexenio 2006-2012. Las Ciudades Rurales Sustentables (CRS), como se llamó la política, fueron experimentadas en el suroriental estado de Chiapas generando un gran debate desde las distintas perspectivas y corrientes teóricas de quienes asumieron una postura de análisis y crítica a dicha estrategia.El artículo es fundamentalmente un extracto de las discusiones, caracterizaciones y algunos resultados de la Tesis de licenciatura titulada "La Ciudad Rural Sustentable 'Santiago El Pinar': una realidad socioeconómica. Referencias de la crisis estructural del Estado" (2015) del mismo autor. Se basa en un estudio etnográfico sobre una de las Ciudades Rurales Sustentables más polémicas y criticadas por sus mismas características y contradicciones: la Ciudad Rural Sustentable "Santiago El Pinar", ubicado en el municipio del mismo nombre en el estado de Chiapas, sureste de México.Se pone de relieve una generalización de las características socioeconómicas del municipio y el estudio de la Ciudad Rural Sustentable, las bases que le dieron origen, las justificaciones gubernamentales. El análisis y las reflexiones de este estudio se sujetan de premisas basadas de otras experiencias y de las teorías de la crisis del modo de reproducción y acumulación capitalista, así como los supuestos que identifican una crisis del Estado mexicano y la relación de las Ciudades Rurales Sustentables con estos eventos.

Palabras Clave: Ciudades Rurales Sustentables, Santiago El Pinar, Chiapas, crisis del capitalismo, Estado mexicano, contrainsurgencia, desarrollo, políticas públicas,
\end{abstract} asistencialismo.

\section{Notes and Perspectives about rural sustaineble Settlement "Santiago El Pinar" the eXperience in Chiapas, South Eastern Mexico}

Aвstract - This article addresses the critical perspective from the vagaries of government policy development of the Mexican state then headed by President Felipe Calderon Hinojosa during the six years from 2006 to 2012. Sustainable Rural Cities (CRS), such as politics was called, were experienced in the southeastern state of Chiapas generating much discussion from different perspectives and theoretical currents who assumed a posture of analysis and criticism of the strategy. The article is basically an extract of discussions, characterizations and some results of the undergraduate thesis entitled "Sustainable Rural City 'Santiago El Pinar': a socioeconomic reality. References to the structural crisis of the state ". It is based on an ethnographic study of one of the most controversial and criticized by its own characteristics and contradictions Sustainable Rural Cities: Sustainable Rural City "Santiago El Pinar", located in the municipality of the same name in the state of Chiapas, southeastern Mexico.It highlights a generalization of the socioeconomic characteristics of the municipality and the study of the Sustainable Rural City, the bases that gave rise, government justifications. The analysis and reflections of this study are subject to assumptions based on other experiences and theories of the crisis playback mode and capitalist accumulation, as well as assumptions that identify a crisis of the Mexican State and the relationship of the Sustainable Rural Cities with these events.

Key Words: Sustainable Rural Cities, Santiago El Pinar, Chiapas, crisis of capitalism, the Mexican State, counterinsurgency, development, public policy, welfarism.

\section{Notas e perspectivas sobre a cidade rural sustentável “Santiago El Pinar” uma experiencia em Chiapas, Sudeste do México}

Resumo - Este artigo trata das políticas governamentais de desenvolvimento do Estado mexicano liderado pelo Presidente da República Felipe Calderón Hinojosa entre 2006-2012. Especialmente, as Cidades Rurais Sustentáveis (CRS). A referida política foi experimentada na região Sul Oriental do estado de Chiapas gerando um grande debate a partir das distintas perspectivas e correntes teóricas. O supracitado artigo é fundamentalmente um extrato das discussões, caracterizações e alguns resultados da Tese de licenciatura intitulada "La Ciudad Rural Sustentable 'Santiago El Pinar': una realidade socioeconômica. Referencias de la crisis estructural del Estado". Se baseia em um estudo etnográfico de uma CRS - experiência polemica e criticada por suas características e contradições: "Santiago El Pinar". O artigo apresenta uma breve descrição das características socioeconômicas do município e o estudo etnográfico da referida CRS, as bases que a originaram e as justificativas governamentais. A análise esta baseada em experiências similares e nas teorías da crise do modo de reprodução e acumulação capitalista, e nos supostos que identificam uma crise do Estado mexicano.

Palavras-Chave: Cidades Rurais Sustentáveis, Santiago El Pinar, Chiapas, crise do capitalismo, Estado mexicano, contrainsurgencia, desenvolvimento, políticas públicas, assistencialismo.

\section{INTRODUCCIÓN}

Si algo ha caracterizado a las formas de gobierno como las que se ejercen en México han sido las políticas sociales de marcado carácter asistencialista. Particularmente Chiapas ha sido un punto de convergencia y de discusión obligatorio dadas las condiciones sociales en las que su sociedad se encuentra delimitada durante décadas y que sigue siendo ahora una realidad.

En la administración de Juan José Sabines Guerrero (20062012) se conoció una particular política de combate de las condiciones sociales innegables en el estado: las Ciudades Rurales Sustentables (CRS). La política de Ciudades Rurales Sustentables en esos años, para Chiapas era entonces algo inédito, novedoso. En el país y en el mundo junto con la CRS de Nuevo Juan del Grijalva en el municipio de Ostuacán inaugurada en 2009 y Santiago El Pinar eran el centro de atención en materia de políticas públicas, ambos representaban la punta de lanza en materia de desarrollo económico en México. Investigadores de diversos países arribaron a Chiapas para conocer y documentar la política mayor difundida: Estados Unidos, Alemania, Brasil, Noruega, Gran Bretaña, entre otros.

La puesta en marcha de la política fue fundamentalmente impulsado por dos razones socio-ambientales: primero, el "binomio dispersión-marginación” que traducido en el lenguaje cotidiano es pobreza en la mayoría de los casos en su condición de "extrema". Segundo, las condiciones de riesgo en las que están expuestas muchas regiones de la geografía chiapaneca por los cambiantes y constantes 
desastres causados por diversos eventos meteorológicos no naturales. Dos objetivos conjugados en el vaivén de la historia estatal por los que se implementaron las CRS.

Paralelo al desarrollo de dicha política, surgieron diferentes modos de lectura desde muy variadas perspectivas. En cada uno de ese amplio espectro de deletreo analítico, incluyendo la Estatal, se trató de explicar, insertar y emparejar a las Ciudades Rurales Sustentables. Se aprecian tres formas: la promoción, la crítica y la neutralidad; este último analiza como un hecho aislado y descarta toda posibilidad de probables implicaciones negativas.

Esta propuesta trata de insertarse en la segunda opción: la Crítica. Lo que significa que mi postura también se inserta dentro del mismo juego ideológico que, al igual que otros, intenta interpretar acertadamente a las CRS con esta forma de lectura.

Entre los dos extremos fundamentalmente materializados por la promoción y la crítica, se halla como menciona Larsson (2012) una "disputa de fetiches". Estos "fetiches" son cambiantes dependiendo del significado que le otorgan los "discursos" que los construyen, a su vez que los "discursos" se mueven al compás de los objetivos de trasfondo que persiguen, de los "intereses en juego".

Dos "intereses en juego" que se desdibujan en polos opuestos: de la promoción, el interés individualista (el mercado, competencia, modernidad, progreso, la ciudad y la concentración); de la crítica, el interés colectivo en tanto mantenga orgánica una correlación de fuerza con otras entidades que persiguen esa misma colectividad. He ahí la diferencia.

Se plantea aquí que las Ciudades Rurales Sustentables no solo fueron una réplica de la ideología capitalista en tanto entendida como método de reproducir dicha ideología, o la ideología que se reapropia de los modos autóctonos de vida de las poblaciones involucradas. Considero que están vinculadas con una forma de sustento de un capitalismo en estado caótico, en crisis continuas y recurrentes desde la revolución mundial de 1968 como señala Wallerstein (2005).

En el Manifiesto Comunista, Marx habla del fin de la lucha de clases, de cómo el Estado adquiere un carácter violento para superar la hegemonía del oprimido.

Para los fines de este estudio, sostengo que en esta fase sistémica, los Estados subordinados al modo de explotación capitalista reestructuran y reacomodan modelos y políticas para contener y desintegrar el brote de movimientos (lo que puede traducirse como violencia), y cuál es la correspondencia de estos eventos con las Ciudades Rurales Sustentables como síntomas de la multiplicidad de la crisis sistémica y de Estado.

Para eso se reafirma y se comprueba con los resultados de los estudios de campo, la incertidumbre donde se inserta la Ciudad Rural Sustentable "Santiago El Pinar" a la que considero la más abandonada e incongruente, y cómo se inserta en un nivel sistémico.

\section{Materiales y Métodos}

\section{Área de estudio}

Santiago El Pinar es un municipio indígena perteneciente a la etnia Tsotsil localizado en la zona II Altos de Chiapas en la región llamada Bloque o Macizo Central (INEGI, 2010). Al norte colinda con el municipio de El Bosque, al sur y oeste con Larráinzar y al este y oeste con Aldama

Tiene una altitud que va desde los 800 y 1200 metros sobre el nivel del mar (msnm), con un promedio de 1680, esto debido a su característica orografía accidentada con lomas y cañadas pronunciadas (Ibíd.; Burguete et al., 2006).

Sus características físico-geográficas permiten poca riqueza y variedad en su ecosistema natural. El cultivo del café, la mayor actividad económica local, forma parte de la biodiversidad vegetal en la zona. Sus características geológicas permiten una formación de la superficie orográfica de sierra alta con laderas tendidas y alto grado de pendientes que impiden el aprovechamiento productivo adecuado del suelo.

El municipio de Santiago El Pinar cuenta con una extensión territorial de $17.76 \mathrm{~km}^{2}$ que representa el $0.02 \%$ del territorio estatal, se encuentra dividido actualmente en 13 localidades registradas con una población total de acuerdo con el Censo de Población y Vivienda de 2010 del INEGI de 3,245 habitantes.

Figura 1. Localización de Santiago El Pinar en la geografía chiapaneca.

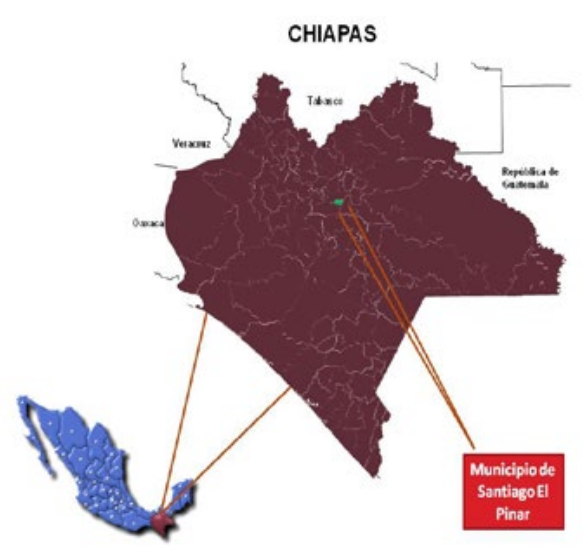

Fuente: Instituto de Población y Ciudades Rurales (IPCR) s/f.

Santiago El Pinar a pesar de ser un nuevo municipio, tiene una larga historia de existencia como pueblo, su trayectoria histórica, como otros tantos pueblos indígenas, comienza desde tiempos precolombinos; de hecho, como lo documentan Burguete et. al (2006) el pueblo sobrevivió a los drásticos tiempos de la era colonial, lo que nos hace suponer que Santiago El Pinar siempre ha existido pese a los “altibajos" debido a los constantes padecimientos de enfermedades que los europeos habían traído a tierras americanas y sobre todo, a los pueblos originarios. No existe historia documentada sobre el origen del pueblo de Santiago, sin embargo, la historia y la tradición oral de los lugareños ha servido para aproximarse a las profundas genealogías cronológicas casi desconocidas.

Calnek (1970) citado en Burguete et. al (2006) menciona que quizá la primera aparición de Santiago en documentos históricos se remonta al año de 1539, aunque no se aclara a que debió la referencia.

Una recapitulación aproximada sobre la historia de Santiago el Pinar permite identificar una ruta de la inmemorable existencia del pueblo, me refiero a que a ninguna otra comunidad tiene parecido a Santiago El Pinar, hoy en día mantiene muchas particularidades identitarias que van desde las usanzas culinarias, los tejidos muy únicos de la ropa tradicional, los modos muy propios del uso de la lengua materna Tsotsil (en particular su dicción y léxico), hasta las costumbres y tradiciones generales que conserva como pueblo. Estas características serían uno de los ejes fundamentales que diera fuerza mayor y coyuntura para su remunicipalización.

Santiago El Pinar comienza a narrar una historia "oficial" y "reconocida" hasta 1882. Esto, un decreto gubernamental del 11 de diciembre de 1882 reconoce a Santiago como municipio

1 La obra de Burguete, Torres y Álvarez es la única obra que documenta y hace un acercamiento importante a la tradición e historia del pueblo de Santiago, aunque otros documentos quizá lo mencionan, sin embargo solo es por algún evento o suceso importantes. 
(municipalidad), junto con otros pueblos vecinos como Santa Martha y Santa María Magdalena (hoy Aldama), el decreto oficializa a 124 "municipalidades" concentradas en 12 departamentos en todo el estado de Chiapas, Santiago formaría parte del Departamento del Centro con sede en San Cristóbal de Las Casas (Burguete et al., 2006).

Durante casi cuatro décadas (39 años), Santiago es reconocido como municipio oficial del estado de Chiapas; en 1921, cuatro años después de la promulgación de la nueva Constitución mexicana, Chiapas lleva a cabo una reforma a su propia Constitución en la que con fecha 5 de febrero de 1921 anuncia la desaparición de 65 municipios, más de la mitad del total registrado (ibíd.).

Entre las 65 reducciones estaban Santiago y sus vecinos Santa Martha y Magdalena, siendo a partir de esas fechas, identificadas solo con el grado de delegaciones, lo que hoy se conoce como agencias municipales. Santiago queda bajo la subordinación del municipio de Larráinzar, el cual a esas fechas todavía seguía siendo también un pueblo dominado por los ladinos.

Como documentan Burguete et al. (2006), la razón principal de la reducción de Santiago a Delegación es su muy reducida población “un censo de población realizado en 1921, reportó que el número de habitantes de Santiago se reducía a 311 personas y que vivían en cuatro localidades, además de la cabecera [...]" (2006).

En los primeros años de vida delegacional, muchos de los pueblos reducidos a esta categoría siguieron buscando la recuperación de su "municipalidad". Muy particularmente Santiago, quizá su mayor resistencia, fue el hecho de no haber dejado de organizar su gobierno tradicional en los diferentes ámbitos de vida comunitaria en cada periodo; sobre todo, de mantener firme el sentimiento de diferencia respecto de los originarios de San Andrés Larráinzar, al cual pertenecen.

En la segunda mitad del siglo XX, acontecieron una serie de sucesos tanto a nivel nacional como internacional que dieron paso a una coyuntura muy particular que significó un parteaguas en la vida nacional: la Guerra Fría, por ejemplo, en la segunda postguerra en la que México se inclinó hacia el imperialismo norteamericano; movimientos sociales como los de 1968 en diversos países del mundo, que en México quedó grabada la radiografía de una lucha y masacre; la apertura mundial del neoliberalismo y la posterior desarticulación de la Unión Soviética (el “fin” de la Guerra Fría); en México, los cambios socioeconómicos generados por la acelerada industrialización y la transición en la política económica; la firma de los Tratados de Libre Comercio de América del Norte (TLCAN); Chiapas en particular, el Congreso Indígena de 1974, hasta el levantamiento armado zapatista en 1994, abonaron a una rebelión generalizada en los pueblos indígenas de Chiapas.

Es así, Santiago estaba inmerso en una coyuntura que era un evento propicio para aglutinar una política de reclamo y de restitución de sus añejos poderes municipales. Los santiagueros, como le llaman a los originarios de Santiago, se fundamentaron básicamente en dos causas: primero el respeto a su diferencia que decían tener respecto de San Andrés Larráinzar, razón que no se niega; y segundo, reclamaban el fin de una larga historia de discriminación y de exclusión por el poder hegemónico de Larráinzar, lo que implicaba -decían- la negativa al acceso de los presupuestos del municipio al que pertenecen. Estas razones eran paso indiscutible para el proceso de su remunicipalización y por lo tanto, conllevaba a la atención de otras demandas como el reconocimiento a sus propias autoridades.

En 1998 en Santiago El Pinar no había servicios básicos de salud, educación, así como infraestructura básica en otras materias, ni inversión pública que diera atención a estas carencias sociales (ibíd.).

En 1973 inicia el proceso de demanda de remunicipalización, impulsados por la movilización indígena en Chiapas y el Congreso
Indígena de 1974 que se celebraría en San Cristóbal de Las Casas. La respuesta gubernamental no fue la adecuada, los santiagueros siguieron luchando por la devolución de su municipalidad (ibíd.)

No obstante, la coyuntura política que trajo el levantamiento del Ejército Zapatista de Liberación Nacional (EZLN) abonó a favor de los santiagueros, esto debido a que el proceso de los llamados Diálogos de San Andrés trajo una ruptura social en este municipio (Larráinzar), en el sentido de que un porcentaje alto de la población estaba ya afiliado a las filas del EZLN, y entonces de repente un desplome del priismo clásico en los municipios indígenas.

Para 1998 Santiago ya se incluye en lista de nuevos municipios, los zapatistas de Santiago argumentaron que esta decisión gubernamental fue una estrategia para fragmentar al municipio autónomo de San Andrés Sakamch'en (oficial de Larráinzar), por lo que se opusieron a la remunicipalización. No obstante, éstos fueron silenciados por la instalación de corporaciones policiacas y del ejército en Santiago (ibíd.), evento que nos aproxima a revelar el objetivo oculto de la remunicipalización: una maniobra contrainsurgente y no la atención de las demandas añejas de los santiagueros, no es casual que dentro del proyecto inicial de remunicipalización, Santiago no figuraba como candidato a ser nuevo municipio; situación que se repitió con el caso de las Ciudades Rurales Sustentables. Lo anterior refleja que para el Estado, Santiago ha sido siempre un pueblo estratégico de contrainsurgencia por su localización intermedia dentro de una zona de influencia zapatista.

En Julio de 1999 se decreta la creación de nuevos municipios y entre ellos “Santiago El Pinar". Comenzó entonces un nuevo proyecto municipal, para Larráinzar fue un rompimiento ante la turbulencia social que dejó el conflicto armado de 1994, tanto para los zapatistas al ser fragmentados en dos municipios como para el partido en el poder (el PRI), pues una fuerza se desprendía de ese poder para formar una estructura propia.

La presión política no solo se debió por el conflicto armado, también porque el municipio habría sido sede de los llamados Diálogos de San Andrés en 1996 y para esas fechas, un desprendimiento político no era propicio sobre todo para el municipio oficial, porque aunque ya fueran "oficialmente" de otro municipio, los zapatistas originarios de Santiago siguieron participando y formando parte del municipio autónomo de San Andrés.

\section{Obtención y análisis de información}

El estudio de campo y el análisis de la Ciudad Rural Sustentable "Santiago El Pinar" se realizaron entre los meses de marzo-agosto de 2014 y enero-febrero de 2015, se dispuso de la aplicación de algunas herramientas básicas que permitieron demostrar el estado real de cosas, fue fundamentalmente un estudio etnográfico para comprender su configuración general y la dinámica de sus partes integrantes. Así también fue crucial la lectura e interpretaciones sistémicas del contexto donde se encuentra inmersa esta política de debate.

Se analiza el funcionamiento de los elementos que articulan la estructura orgánica de la Ciudad Rural, donde funcionamiento lo defino como la equivalencia del nivel de objetivos cumplidos de dicha política, y cuánto de cada elemento cumplió su papel para hacer funcionar al complejo.

Cabe mencionar que el estudio de campo y el desarrollo de las actividades consiguientes se vieron coartados por eventos sociales que inicialmente no estaban contemplados en las delimitaciones del trabajo. Me refiero a problemas comunitarios en los que se vio envuelto el municipio de Santiago El Pinar en toda la segunda mitad del 2014 y a lo largo del 2015, el cual consistió en el destape de una supuesta evasión fiscal que las autoridades del periodo 2012-2015 
cometieron en el ejercicio del poder municipal.

Lo cierto es que éste tuvo orígenes relacionados con desfases políticos entre grupos partidistas en pugna por el poder en el municipio. Esta circunstancia particular atenuó la posibilidad de mayor debate con los habitantes sobre el problema de investigación dado que no había otro tema de discusión más que los problemas que estaban afectando al tejido comunitario del pequeño municipio. A ello se agrega la imposibilidad ya existente por parte de las diversas autoridades gubernamentales al acceso a la información verídica referente a las CRS.

No obstante, se toma en cuenta la información difundida en el Cuarto y Quinto Informe de Gobierno de 2010 y 2012 respectivamente, así como la información disponible en el sitio web del Instituto de Población y Ciudades Rurales (IPCR).

Subrayo de manera central que la información recabada en las entrevistas y pláticas informales con los habitantes de Santiago El Pinar que generosamente me facilitaron, serán los rellenos de los grandes vacíos de información que fui encontrando en tanto más me adentraba a la complejidad del hecho. Teóricamente estas herramientas pueden reconocerse como Metodología: el método crítico y la Investigación Acción Participativa (IAP) o sociología de la liberación se basan en una interacción y dialogo con los sujetos involucrados.

\section{Resultados}

Características generales de la Ciudad Rural Sustentable "Santiago El Pinar" En el sitio de internet del Instituto de Población y Ciudades Rurales (IPCR) puede apreciarse una información muy restringida de "Santiago El Pinar" en comparación con "Nuevo Juan del Grijalva". Entre lo poco, figuran dos mapas: el de ubicación geográfica del municipio y el de localización de la Ciudad Rural en el territorio municipal donde aparecen también otros elementos importantes como las comunidades que fueron reubicadas; además puede encontrarse un plano de la Ciudad de recién creación donde se aprecian los trazos urbanos y la localización de la infraestructura.

Figura 2. Ubicación de la CRS en el territorio municipal. En este mapa existen contradicciones, las comunidades de Xchuch y Choyó no fueron reubicadas, mientras que San Antonio Buenavista que fue reubicada no aparece.

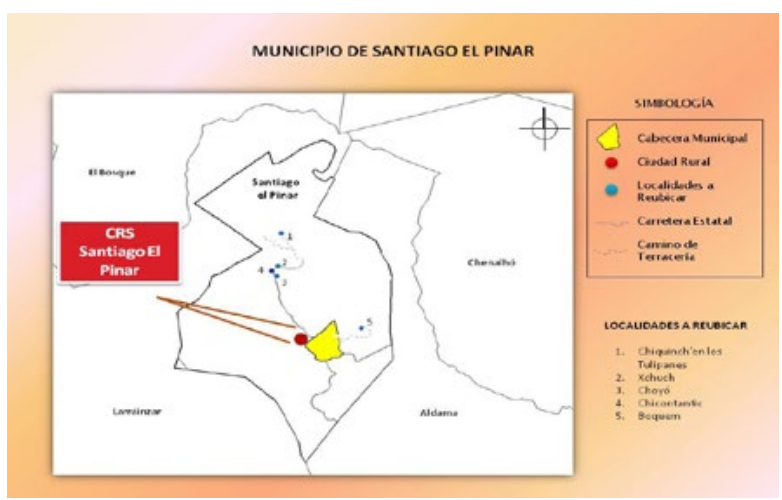

Fuente: Instituto de Población y Ciudades Rurales s/f.

La Ciudad Rural Sustentable se localiza a muy poca distancia de la cabecera municipal, aproximadamente a 500 metros, separados solo de una pequeña cañada. En la descripción del área de estudio se rescata que la superficie de Santiago El Pinar se caracteriza por su "accidentada orografía”, la Ciudad Rural se edificó en las laderas de una loma fuertemente marcada por una pendiente natural que pone en severa duda la sustentabilidad ambiental y la prevención de desastres que supuestamente caracterizan a las CRS.

Larsson documenta que según versiones de habitantes de Santiago El Pinar, el cerro en el que fue instalada la Ciudad Rural tiene una importancia histórica y es sagrada "es el lugar de los antepasados, donde se juntan a hacer fiesta todas las noches" (2012). Lo cierto es que otros testimonios documentan que "en Santiago El Pinar hay tristeza en los viejos, que ven desaparecer cafetales, milpas, platanares y su manera de vivir" como mencionó Herman Bellinghausen en una crítica al programa.

En el Cuarto Informe de Gobierno, se comunica que para la edificación de la Ciudad Rural se adquirió un predio de 38.3 hectáreas para reubicar a cuatro localidades consideradas dispersas: Chiquinch'en los Tulipanes, San Antonio Buenavista, Boquem y Chimcomtantik (Chik'omtantik en la dicción de Santiago El Pinar, una comunidad de nueva creación que está sin registro, en los estudios recientes del INEGI no aparece documentada), además se considera "fortalecer la infraestructura de la cabecera municipal y de cuatro localidades conurbadas que son Nínamo [Ninamhó en términos locales], Pushilhó, Pechultón y Nachón” (Gobierno del Estado, 2010).

De acuerdo con fuentes gubernamentales como señala Larsson, para determinar el grado de dispersión poblacional utilizaron un indicador creado por el geógrafo Albert Demangeon, Larsson menciona:

"Para elaborar los índices de dispersión, se utiliza un esquema que él propuso. Este “Índice Demangeon” se basa en una fórmula donde se multiplica el número de habitantes fuera de la cabecera con el número de localidades. Esta suma se divide entre la población total del municipio, incluyendo a la cabecera [...]. Usando este índice, Santiago el Pinar se encuentra en el lugar 110 de los 119 municipios de Chiapas [...], es decir, entre los diez municipios con menos dispersión del estado (Larsson, 2012: 77).

Tomando como referencia los datos recabados por el INEGI en el 2010, el Índice Demangeon o Índice de dispersión-concentración (K), para Santiago El Pinar quedaría de la siguiente manera utilizando la fórmula Demangeon:

$$
\mathrm{K}=\left(\mathrm{E}^{*} \mathrm{~N}\right) / \mathrm{T} \quad \propto \mathrm{K}=(3245-1072) 12 / 3245 \propto \mathrm{K}=8.03
$$

Donde

$\mathrm{T}=$ Poblacion total.

$\mathrm{E}=$ Población dispersa.

$\mathrm{N}=$ Número total de localidades.

Albert Demangeon estableció un rango de valores de referencia para refutar si el resultado obtenido representa un índice de concentración y/o dispersión alto, bajo o normal. De 0 a 0,1 es concentración máxima; 0,1 a 1 concentración normal; de 1 a 50 dispersión normal y de 50 a 100 dispersión máxima. Si bien, el valor de 8.03 puntos para Santiago El Pinar, teniendo como referencia el Índice Demangeon, no indica que haya concentración normal, como tampoco concentración cero.

Sin embargo, 8.03 puntos (en un rango de 1 a 50 en cuanto a dispersión poblacional) significa que hay una densidad relativamente adecuada en su territorio; como señala Larsson, figura entre los diez municipio con menor dispersión poblacional a nivel estatal; por lo tanto, no existe ninguna relación ni justificación del argumento gubernamental sobre la supuesta dispersión poblacional del municipio de Santiago El Pinar.

Otras fuentes consideran a una población "rural dispersa" cuando ésta cuenta con un número de habitantes inferior de 500 y localizado de 5 a más kilómetros de otra localidad también de menos de 500 habitantes dentro del radio territorial de un municipio (ver 
Dávila et al., 2002). Si tomamos en cuenta los kilómetros cuadrados que abarca el territorio municipal de Santiago El Pinar, los cálculos en distancia entre localidades no arrojan resultados de dispersión poblacional, quizá remotamente la localidad de Chikinch'en que figura como la localidad más alejada de la cabecera municipal con tan solo 59 habitantes y localizada aproximadamente a seis kilómetros de ésta, pero a menos de un kilómetro se encuentra la localidad de Santiago el Relicario.

Hasta ahí sobre las medidas de dispersión. En el mismo documento, es decir, en el Cuarto Informe de Gobierno se da a conocer que cada lote de la Ciudad Rural tendrá una superficie de 300 metros cuadrados $(\mathrm{m} 2)$ de 10x30 metros, donde se edificará toda la infraestructura, señala:

Se construyen más de 140 viviendas nuevas de $36 \mathrm{~m} 2[\ldots]$ que contarán con dos cuartos, cocina, sala-comedor, baño y pórtico; dispondrán de los servicios de agua potable, drenaje y electrificación; además se rehabilitarán y mejorarán más de 300 viviendas de las localidades conurbadas.

La ciudad contará con infraestructura urbana: jardín de niños, primaria, espacios religiosos, centro social popular, industria alimentaria, módulo de vigilancia, parque, cancha de usos múltiples, juegos infantiles, corredor comercial, entre otros.

En infraestructura básica se contará con agua potable con obra de captación, líneas de conducción, distribución y alimentación, tanques de almacenamiento y una planta potabilizadora, además de drenaje sanitario con una red de alcantarillado sanitario con descargas domiciliarias, colectores y una planta de tratamiento de aguas residuales; se contará con una red de distribución eléctrica subterránea y una subestación eléctrica y red domiciliaria, además de alumbrado público y vialidades pavimentadas. (Gobierno del Estado, 2010: 81, 82).

De todos los datos anteriores existen variaciones debido a que hubo varias fuentes que informaron en diferentes momentos y contextos sobre la infraestructura de la Ciudad Rural de Santiago El Pinar. El Instituto de Población y Ciudades Rurales (s/f) promueve en su página de Internet que son 33.9 hectáreas de predio donde se edificó la infraestructura urbana, en él se construyeron 115 viviendas, pero también señala en su sección proyecto que son 38.3 hectáreas donde se construyeron 135 viviendas. Además, 350 viviendas nuevas en predios familiares preexistentes, así como 489 acciones de mejoramiento de vivienda también ya existentes (IPCR, s/f).

En la misma página, en la sección de proyecto, se recalca "una planta ensambladora, 6 invernaderos, 4 hectáreas de gladiolos, micro túneles para la producción de hortalizas y granjas avícolas" (IPCR, $\mathrm{s} / \mathrm{f}: \mathrm{s} / \mathrm{p})$.

Se puede corroborar con los datos anteriores que el radio de influencia del Sistema de Ciudad Rural Sustentable no se aísla solamente en las casi 40 hectáreas del predio donde se instaló, cubre otras áreas del municipio como las llamadas "localidades conurbadas" a través del mejoramiento y construcción de nuevas viviendas y de la instalación de los servicios básicos; lo que genera un mejoramiento de la imagen municipal como lo anunciarían en los diversos medios.

No obstante, la estancia de campo arroja resultados distintos y hasta cierto grado, contradictorios. Se registra un cambio importante que reafirma las incongruencias en las fuentes gubernamentales que describieron a la Ciudad Rural Sustentable "Santiago El Pinar", esto si el análisis parte desde el punto de vista de cuánto de los servicios e infraestructura han funcionado en comparación con su existencia real y física.

"Santiago El Pinar", además de su edificación en las laderas del cerro y que se encuentra casi pegada a la cabecera municipal, sobre su asentamiento de casi 40 hectáreas de superficie también se halla que tiene, entre calles y avenidas vacías, nueve venas por donde fluye el vacío; cinco cuadras (manzanas) donde se levantan las casas y su compleja infraestructura urbana. Sus cortas calles y avenidas son de concreto, banquetas pintadas de amarillo y señalamientos de vialidad.

Cuenta con un sistema de drenaje y alcantarillado sanitario; un sistema de red de energía eléctrica subterráneo que se distribuye a lo largo de la ciudad y en las viviendas y en los diferentes establecimientos e infraestructura existentes; así también, una red de distribución de agua potable con un tanque de almacenamiento propio y un servicio completo de alumbrado público.

Entre los inmuebles más importantes figuran una escuela de preescolar "Gabriela Mistral”; una primaria "Enrique Rebsamen”; dos canchas de basquetbol, también conocido como de usos múltiples y una pequeña área de juegos infantiles.

En el ámbito económico-productivo se encuentran una Planta Ensambladora "Santiago El Pinar"; cinco Granjas Integrales de Aves Ponedoras; cuatro naves de Invernaderos de rosas; establecimiento de Procesadora de café: Cuenca Cafetalera "Santiago el Pinar"; una Cafetería "El Pinar"; Súper Chiapas (re etiquetado con el nombre de Mini Súper); una Parada de transportes; Mercado constituido por dos naves para el abasto de la población del centro urbano; y el Centro de Salud con Servicios Ampliados (CSSA) donde se acomodan las esperanzas de la población.

Sobre esta descripción uno pregunta: ¿Quién puede juzgar una ciudad moderna y de color de rosa? ¿Quién pudiera creer que en esa ciudad nada funciona y es una ciudad fantasma? Estas paradojas reúnen las miradas que ponen en medio de las disputas y las especulaciones a la CRS de Santiago El Pinar. Y es otra paradoja pensar en las razones por las que nada ha funcionado en la Ciudad Rural donde se concentran los servicios y las infraestructuras.

Discusión y algunas evaluaciones

Si bien, en esta parte específica del estudio, compete una discusión sobre las posibilidades y alternativas al proyecto de Ciudades Rurales Sustentables, no obstante, reafirmaré de acuerdo con los criterios de este escrito la crítica al programa, señalando algunos factores que en la implementación de las Ciudades Rurales se traducen en violación a Derechos exclusivos de los pueblos involucrados, que es otra causa de su disfuncionamiento, y cómo éstos responden a una jerarquía de poder desde el modo capitalista de explotación.

De acuerdo con los resultados de los estudios realizados por los grupos de las Universidades de Cornell y Míchigan, se realizaron algunas recomendaciones al proyecto para rectificar sus desvíos y obtener los objetivos planteados por el mismo. El grupo de la "Michigan Ross School of Business" fue financiado por la Fundación Azteca y el Grupo Salinas (Larsson, 2012) para que realizaran ellos los correspondientes estudios mercadotécnicos y las viabilidades económicas de las Ciudades Rurales Sustentables. Sus recomendaciones van ligadas a los planteamientos gubernamentales, pero con el fin de adecuar el proyecto a los objetivos por los que fue planeado.

Señalan por ejemplo, haciendo mayor énfasis a la CRS "Nuevo Juan del Grijalva”, que la dispersión poblacional y la geografía accidentada son los componentes primordiales para que la población siga siendo vulnerable a las condiciones de pobreza causados por la mal llamada marginación. El estudio también se clasificó en ejes, muy cercanos a los Componentes o Subsistemas manejados en el discurso gubernamental, la recomendación fundamental del estudio es que la población tenga mayor participación en la planeación de los proyectos sociales y económicos a través de una relación de comunicación que 
permita trazar mejores viabilidades de la Ciudad Rural Sustentable.

En el eje específicamente sobre economía, se insertan ahí cuestiones meramente de mercado y negocios, se proyectan las perspectivas para hacer de la CRS un centro de población netamente productivo y sustentable, también recomiendan crear unidades de negocios donde puedan ser comercializadas la producción local incentivados por los proyectos productivos que se implementaron, así como el aprovechamiento de potenciales naturales (llamadas ventajas comparativas) que la región ofrece, estableciendo relaciones comerciales con los mercados externos bajo una "Asesoraría de Negocios" (Larsson, 2012). Lo anterior tiene parecido y son algunos de los planteamientos principales de la Geografía Económica que a inicios de los 90 Paul Krugman insertara en la ciencia económica.

Como es evidente, las sugerencias realizadas por este estudio tienen que ver mucho con la lógica de una economía de mercado y poco desviado del planteamiento que el Estado realizó con referencia a las Ciudades Rurales. El grupo de la Universidad de Cornell, por su parte, señala también errores cometidos en la implementación del programa y recalca las estrategias que considera adecuadas para su mejor funcionamiento y evitar -señala- destinar al fracaso millonarias inversiones. Puntualizan entre otras observaciones, el erróneo "enfoque de arriba hacia abajo" en la implementación de las políticas públicas, así como el aislamiento de estas "Ciudades" con economías preexistentes (es decir, poblaciones), que señalan, son factores de disfuncionamiento; concluyen:

Ubicarse geográficamente más cerca de otras áreas urbanas hubiera beneficiado a Nuevo Juan del Grijalva [...]. Esta proximidad cercana no sólo hubiera desembocado en la apertura de mercados para la producción y a la vez el consumo, sino que hubiera beneficiado a muchas más personas que las existentes 410 viviendas contempladas en la construcción de esta nueva ciudad" (De León et al. 2010; citado en Libert, 2012: 85, traducción de Libert).

Sin embargo, si aplicamos la tesis anterior para "Santiago El Pinar" que fue instalada paralela a la cabecera municipal, de todas formas no encuentra sustento a pesar de que algunos de los proyectos e infraestructura implícitos fueron edificados tanto en la cabecera como en las comunidades conurbadas.

Las razones de ello tienen que ver, como se ha señalado, con la ausencia de servicios básicos en el centro poblacional que fue el factor eje que desembocó al abandono casi total de la Ciudad, para los proyectos económico-productivos estos servicios eran materia prima, se agrega también la ausencia de un mercado de consumo definido, sea local o externo, que era fundamental para su eficiencia. A ello se suma los inadecuados trazos y conceptos culturales que se manejaron en "Santiago El Pinar", nada armónicos con el concepto propio de cultura y de los usos tradicionales que entonces tenía vigencia.

El estudio del grupo de Cornell para el caso de "Santiago El Pinar" señala que:

"Estos resultados [de disfuncionamiento] nos llevan a concluir que sigue siendo por la falta de transparencia que rodea a los objetivos y la implementación del Programa de CRS. La falta de transparencia priva a los residentes de la información importante que permite tomar decisiones informadas que afectan sus vidas y las vidas de sus familias, por lo tanto privarlos de su derecho a la libre determinación.” (Arnold et. al., 2011: 18; traducción propia)

El estudio ve como factor de repunte de las Ciudades Rurales Sustentables las asesorías en el ámbito económico-productivo, así como la interacción con otros mercados mediante el aprovechamiento de las llamadas "economías de escala" de nivel local o regional. Pero también apuntan que el disfuncionamiento es causado por la falta de generación de empleos que pueda propiciar el incremento de la demanda local en los establecimientos comerciales. De acuerdo a su análisis, se da en estas nuevas "Ciudades" una transición de economía de autoconsumo a una Urban Market Economy (Economía de Mercado Urbana), donde la producción no es de autoconsumo sino de intercambios y exportación con y hacia nuevos espacios mercantiles entre economías regionales o suprarregionales, eventos que nunca se dieron (ver Arnold et al., 2011).

Recomiendan por lo tanto la no creación de más Greenfield Constructions (construcción en campos verdes), ellos consideran que "Si la densidad es una solución a los problemas de la dispersión, la marginalización, y la pobreza, entonces la posible expansión de centros urbanos establecidos en vez de la construcción de una nueva ciudad entera es una alternativa viable al actual programa CRS” (De León et al., 2010; citado en Libert, traducción de Libert).

Concluyen que la "falta de éxito" de los proyectos productivos no se debe a las formas propias de sustento de las comunidades, sino por los trazos realizados al programa, diferente de las medidas culturales de la población, por tales razones la estrategia de Ciudades Rurales "no cumplirán" con los objetivos de abatir la dispersión poblacional y menos de mitigar los embates de la naturaleza. Sugieren como alternativa el fortalecimiento de las poblaciones "preexistentes" donde sea más efectivo el cumplimiento de los objetivos "subyacentes" y una administración "menos escandalosa" de las inversiones realizadas (Ver De León et al., 2010).

Arnold et.al. advierten que "la extensión del daño es alarmante" (2011: 31), así como el proceso de reasentamiento puede prolongar consecuencias negativas; pasar de vivir de una localidad rural a un centro de población más grande implica para ellos "un cambio" en el estilo de vida, la estructura social y organización comunitaria de la población e "interrumpe" la cohesión familiar basadas en identidades tradicionales propias (ibídem; traducción propia).

En el caso de "Santiago El Pinar", han expuesto a la población a los riesgos de derrumbes y deslaves provocados por la deforestación que gracias a la construcción de la Ciudad Rural se han enfatizado, pero sobre todo, es la pendiente del cerro que está en condiciones de sufrir deslizamientos y es sobre la que se erigieron las casas de la Ciudad Rural Sustentable.

Los anteriores son estudios realizados con objeto de evaluar el funcionamiento de las Ciudades Rurales desde la perspectiva del cumplimiento de los objetivos que fueron perseguidos. No obstante, hay otros análisis en los que se compromete las políticas del Estado y los argumentos que justificó la construcción de estos complejos infraestructurales, podemos dar cita con el artículo titulado "El sur también existe: un ensayo sobre el desarrollo regional de México” de Enrique Dávila, Georgina Kessel y Santiago Levy (2002).

"El sur también existe" es un ensayo que fue polémico en el marco de la justificación gubernamental de las Ciudades Rurales Sustentables, señalándose como la base teórica de dicho programa, en el estudio se señala que:

La dispersión poblacional frena el aprovechamiento de las economías de escala en la provisión de servicios públicos [...] el tamaño mínimo de población para aprovechar las economías de escala en la dotación de servicios básicos de educación y salud, así como de abastecimiento de agua potable y drenaje, es de alrededor de 1,500 habitantes. (Dávila, et. al., 2002: 209)

Libert (2012) y Pickard (2012) probablemente es con estas consideraciones que sustentan que el Estado se fundamentó en "El sur también existe” para implementar las Ciudades Rurales Sustentables en Chiapas. Sin embargo, los mismos autores del artículo invitan a leer a Krugman para ampliar esa tesis, por lo tanto, como también 
menciona Larsson (2012), Krugman es probablemente el teórico principal del artículo citado y por supuesto de las CRS con su propuesta de "Geografía Económica", también es la base de los planteamientos del Banco Mundial de 2008 con el informe llamado "Una Nueva Geografía Económica", informe que Libert y Pickard también consideran como las bases teóricas que justificaron al programa de Ciudades Rurales.

Si bien, Dávila et al. (2002) apuntan que la dispersión poblacional es el factor que imposibilita el aprovechamiento de las “economías de escala” y de la dotación de servicios básicos, también reconocen que son las políticas públicas mal planteadas del gobierno, por no decir asistencialistas, que frena el aprovechamiento de lo que se conoce como las "ventajas comparativas" para propiciar el crecimiento autosostenido y autónomo de las zonas con mayor rezago social. Chiapas posee una riqueza natural exuberante que lo clasifica como una de las zonas con mayor ventaja comparativa, pero las políticas aplicadas sobre ellas, han sido sumamente restrictivas respecto de los derechos económicos y de autodeterminación de la población, el ensayo señala:

La tesis central es que las políticas públicas instrumentadas por el gobierno federal en las últimas cinco o seis décadas implícitamente han desalentado el desarrollo económico de Chiapas y la región sureste en general [...]. (Dávila et al., 209: 2002)

Consideran que "la dispersión poblacional es, en parte, resultado de las políticas públicas", ponen como ejemplos a la alza de precios del maíz que obliga a las poblaciones más pobres a devastar zonas forestales para convertirlos en campos de cultivo de autoconsumo (aunque el aumento del precio de los productos tiene que ver más con políticas fiscales), argumentan también que la política en materia agraria injiere en la "ubicación, tamaño y características de los asentamiento humanos" en las zonas rurales (ver Dávila et. al., 2002). Es decir, son las mismas políticas gubernamentales que crean condiciones y coyunturas propicias para implementar otras con fines netamente empresariales mediante el saqueo desmedido de los recursos naturales (en México la Reforma Energética por ejemplo), pero también permite políticas estratégicas de contrainsurgencia para retener el descontento social, como es el caso particular de "Santiago El Pinar".

Las conclusiones del artículo sobre el (sub)desarrollo económico del sur-sureste, sobre todo haciendo énfasis en el estado de Chiapas, dan otra evidencia de los objetivos políticos implícitos en las Ciudades Rurales Sustentables, más allá de aquello de atender los problemas de dispersión poblacional y soslayar los eventos "naturales" que ponen en entredicho la supervivencia misma del ser humano en algunas zonas geográficas del estado, país y otros.

Podemos formular la siguiente pregunta: ¿El Estado tomó en cuenta expectativas relacionadas con las que se plantean en el ensayo?. Si nos referimos a los pocos proyectos productivos implementados en la Ciudad Rural de Santiago El Pinar, encontramos que éstos se mantuvieron solo con recursos de carácter asistencialista especialmente destinados para esas actividades, como es el caso específico de la Planta Ensambladora.

Todo ello, se relaciona con estudios en los que no sólo se señalan los errores en la implementación del programa de CRS, sino argumentan que responde a una alta jerarquía y estructura de poderes que sólo pueden ser comprendidas desde la perspectiva sistémica. Es decir, apuntan que las Ciudades Rurales son replica de un amplio programa de políticas de control desde el sistema y modo de explotación capitalista.

Wilson (2009) encuentra una continuación del Proyecto Mesoamérica (antes Plan Puebla Panamá) en las CRS, señala que en dicho plan, entonces se denominó "Centros de Integración Rural". Para Wilson, el establecimiento de las Ciudades Rurales implica una desarticulación de los Caracoles zapatistas, además de la inserción del campesino y el originario al modo de acumulación capitalista.

Esta relación de la política de Ciudades Rurales Sustentables con políticas de corte neoliberal como es el Proyecto Mesoamérica, son a su vez, políticas, planes y modelos ramas de las prácticas del capitalismo del desastre como hace notar Klein (2007) en "La doctrina del Shock: el auge del capitalismo del desastre". Un sustento de esta teoría de imposición del capitalismo en las Ciudades Rurales Sustentables, discusión en la que Libert (2012) encuentra mayor énfasis en "Nuevo Juan del Grijalva”, donde se hace más que evidente el "modus operandi clásico" de aprovechar emergencias para imponer las políticas de despojo de territorios y recursos para convertir las riquezas naturales en riquezas monetarias.

Esta implementación de las políticas capitalistas en programas de ámbito local puede descifrarse en una interpretación simbólica de los trazos, rasgos y la imagen de la Ciudad Rural Sustentable. En las formas de presentar teórica y físicamente a la "Ciudad" van ocultos los rasgos característicos del capitalismo que se suma al previo estado idealizado (dominado) del sujeto de la comunidad rural, sobre todo del mundo indígena y campesino sobre su concepción de lo urbano, esta condición ideológica bajo la dominación capitalista apunta a concebir, captar e idealizar que lo urbano, es decir, la "Ciudad", es la solución de la pobreza en el mundo rural, la miseria de lo comunitario, lo cotidiano de la miseria y la carencia en la comunidad.

Concibe a la "Ciudad" con sus marcos y sus trazos como espejo del desarrollo, del bienestar. Los vidrios y los cristales de los edificios, las amplias calles e interminables avenidas, los miles de autos congestionados, la iluminación, son para el sujeto de la ruralidad sinónimos de esperanza, de empleo, de oportunidades. De esa premisa parte la mayoría de los millones de casos del gran "sueño americano" y del "sueño mexicano" para los venidos del mas del Sur que se esfuman en el desierto del norte, en el Bravo y en el Suchiate en su caso.

En ese peculiar modo que el capitalismo hace ver, introduce el Estado en lo rural el concepto de "Ciudad" ya aceptado previamente por la población objetivo. Así se presentó la Ciudad Rural Sustentable en Santiago El Pinar, como la ciudad de la esperanza, donde no habrá pobreza sino bienestar. El trazo urbano, la infraestructura económica y comercial, los Proyectos Productivos como la Planta Ensambladora etiquetado de “fábrica” por los pobladores como sinónimo de empleos; la imagen de la "Ciudad", fueron equivalentes a bienestar económico. La sucursal de Banchiapas fue el símbolo y la representación del capital, del dinero que "mueve" al mundo, del interés individualista y la competencia capitalista.

En esta otra forma de explicación, de simbolismos, se puede contrastar la puesta en práctica de esa concepción errónea del originario respecto de la imagen que aparenta la "Ciudad", lo que nos permite ahora comparar entre "Ciudad fantasma" y una "Ciudad monstruo" (la Ciudad de México por ejemplo) donde las periferias del mundo moderno se concentran en cinturones de miseria cada vez más anchos. Ambas imágenes representan algo en común: las carencias, en algunos casos similares, en otros, divergentes.

He aquí un conjunto de incongruencias y desconexiones entre el Estado y la sociedad puestos en práctica en la implementación de las Ciudades Rurales Sustentables junto con los objetivos implícitos, entre ellos, el ejercicio de los derechos sociales, que equivale a la violación a otros derechos fundamentales que se encuentran estipulados no solo en la Constitución mexicana, sino también plasmados en estatutos internacionales que el gobierno mexicano ha suscrito. 
En el análisis a la CRS "Santiago El Pinar" respecto al cumplimiento de los derechos sociales, la Universidad de Cornell argumenta la violación a normas internacionales de derechos, de manera central al de la libre determinación de los pueblos avalado por la ONU y consagrado en esencia en los Objetivos de Desarrollo del Milenio (ODM), concepto internacional en el que se alineó los objetivos de las Ciudades Rurales Sustentables en su planteamiento teórico.

Por su parte, el Informe de la Red Por la Paz y el Colectivo de Análisis e Información Kolectiva (KAIK), hace un estudio exhaustivo sobre la serie de derechos humanos que viola la política de Ciudades Rurales. Mencionan fundamentalmente la violación al "Derecho a la Libre Determinación y Autonomía de los Pueblos Indígenas", de donde se deprende otras violaciones a los derechos, como el Derecho a la consulta, Derecho a la información, Derecho a la Participación, Derecho al trabajo, Derecho a una vivienda adecuada, Derecho a la salud y el Derecho a la educación; así como los llamados Derechos Transversales como el Derecho a la tierra y el territorio, el Derecho a un nivel de vida adecuado, los Derechos culturales como el respeto de usos y costumbres y el Derecho al disfrute de la propiedad y a un pago justo en caso de expropiación. Señala:

[...] el derecho a la libre determinación incluye no solo que los pueblos puedan determinar libremente su organización política, sino también su desarrollo económico, social y cultural, por lo que abarca una gran variedad de otros derechos humanos. [Que] son violentados por el Estado en perjuicio de la población afectada por el programa CRS, lo que significa en sí mismo una violación al derecho a la libre determinación. (Red Por la Paz Chiapas y CAIK, 2012: 47)

La misma fuente apunta que todos estos derechos señalados están consagrados además de la Constitución Política de los Estados Unidos Mexicanos en los siguientes “marcos normativos”: Declaración de las Naciones Unidas sobre los Derechos de los Pueblos Indígenas; Convenio 169 de la Organización Internacional del Trabajo (OIT); Ley de Desarrollo Social; Ley Federal de Transparencia y Acceso a la Información Pública Gubernamental; Constitución Política del Estado de Chiapas; Declaración Universal de los Derechos Humanos; Pacto Internacional de Derechos Económicos, Sociales y Culturales; Protocolo Adicional a la Convención Americana de Derechos Humanos; Ley Federal del Trabajo; Ley General de la Salud y Ley General de la Educación fundamentalmente. Documentos y Derechos que los distintos gobiernos mexicanos han signado y respaldado (ver Red Por la Paz Chiapas y CAIK, 2012).

El incumplimiento y la violación de estas normas internacionales han permitido la incompetencia socioeconómica y el disfuncionamiento de las Ciudades Rurales en su conjunto. En "Santiago El Pinar", existe una perspectiva económica llena de perplejidades; podríamos hacer aproximaciones mediante números, ecuaciones, gráficas y otros cálculos aritméticos e incluso algebraicos, -a ver quién nos echaba la mano-, pero lo cierto es que es ahora una cuestión sujeta a las fluctuaciones sistémicas y no a reducciones con sumas y con restas.

Esta experiencia que dejó la política de Ciudades Rurales Sustentables ha obligado a leer las "letras chiquitas" de las recetas, de sus planteamientos, paralogismos, sofismas y de la producción de discursos con las que fueron acompañados. Por lo tanto, la discusión de este trabajo se resume en los siguientes puntos:

I. - La Ciudad Rural Sustentable "Santiago El Pinar" es un fracaso total. El estudio etnográfico de donde resultó un análisis y contextualización socioeconómica de las diferentes infraestructuras intrínsecas a la Ciudad Rural, arroja resultados contradictorios con respecto a los anunciados por el Estado.
En "Santiago El Pinar” contabilizando los tres servicios básicos que son el agua potable, el drenaje sanitario y la energía eléctrica, son en total 14 infraestructuras diferentes que se encuentran establecidas dentro del predio que es la Ciudad Rural. De ellas, solo tres funcionan con irregularidades: el Centro de Salud con Servicios Ampliados, la Escuela primaria y los establecimientos de Granjas Integrales de Aves Ponedoras, es decir, calculado de ese modo, más del 80 por ciento de la Ciudad Rural es un fracaso, sin tomar en cuenta el total de las viviendas que funcionan solo menos del 14 por ciento, sino como una sola infraestructura.

No obstante, en Entrevista con los directivos de estos centros, el CSSA funciona porque depende de la Secretaria de Salud, mientras que la Escuela Primaria funciona porque es la misma que se localizaba en la plaza de la cabecera municipal, fue reubicada con objeto de realzarla como Ciudad Rural. El caso de las Granjas Avícolas ahora funciona con recursos propios de los "granjeros", pues el subsidio inicial no perduró ante la ausencia de mercados de consumo y de servicios básicos para su funcionamiento.

Uno de los elementos más importantes de la Ciudad Rural: la vivienda, ha sido polémico y centro de disputa debido a sus condiciones, estas son algunas de sus características: se construyeron un total de 116 viviendas con medidas de 5 por 6 metros $\left(30 \mathrm{~m}^{2}\right)$, edificado sobre un lote de $300 \mathrm{~m}^{2}$ de 10 por 30 metros. Se subdivide en cuatro partes no iguales: la habitación principal que mide 2.35 por 3 metros, insuficiente para familias grandes que predomina en la mayor parte de las familias mexicanas; la habitación secundaria con una superficie de 2.35 por 2.15 metros; le sigue una "sala" que se encuentra junto a la entrada principal, con una superficie de 3.6 por 2.35 metros. Existe un espacio vacío junto a la sala, se considera que es la cocina, mide 2.5 por 1.42 metros (sin posibilidades de espacio para el fogón, elemento típico en la región, por lo tanto son construcciones culturalmente inadecuadas y es una clara violación a los derechos de la libre determinación); por último, el baño completo.

En cuanto a los materiales utilizados en la edificación ha sido un espacio de desilusión y de reclamos, fundamentalmente por la calidad y su eficiencia que al ser utilizados en la construcción de las viviendas no cubre las necesidades humanas ni las recomendaciones mínimas en esta materia en espacios y contextos como lo es la Ciudad Rural Sustentable. La tablaroca, material de construcción utilizado, es un derivado de concreto prefabricado que se usa como pared en determinadas circunstancias, nada adecuado para las CRS. El techo es térmico, compuesto de unicel con una cubierta exterior de cartón y en el interior una capa de triplay, el piso es también de triplay con un forro de plástico.

De las 116 viviendas construidas en la Ciudad Rural Sustentable “Santiago El Pinar", que ahora sólo restan 115 porque una fue absorbida por un derrumbe, hasta a inicios de 2015 estaban siendo habitadas solo 16 viviendas, ninguna era rentada, lo que significa que las 16 son ocupadas por familias de Santiago El Pinar.

Exactamente 100 casitas de madera están abandonadas, (respetando el derrumbe sería 99); en términos porcentuales, las habitadas solo representan un 14 por ciento, lo que significa que casi el 90 por ciento están totalmente abandonadas, de ellas, no menos del 50 por ciento están destrozadas e inhabitables y el resto parece ser que permanecen selladas pero inservibles.

En cuanto a servicios básicos dentro de la vivienda no funcionan, la electricidad la reconectaron los mismos habitantes y con sus propios recursos, mientras que la ausencia de agua potable o entubada ha sido uno de los mayores retos de los pocos pobladores "sólo llenan los tinacos cuando viene alguien del gobierno" comentan, por lo tanto el sistema de drenaje se encuentra vacío por falta de agua, además de los saqueos que presenta en las líneas de conducción. 
La situación de la falta de energía eléctrica en la Ciudad Rural afectó considerablemente a muchos de los establecimientos del centro urbano, particularmente el Centro de Salud con Servicios Ampliados (CSSA) como uno de los servicios de mayor importancia y que refleja gran parte del "funcionamiento" de la CRS. La Dirección del Centro argumenta respecto a las muestras de laboratorio que toman: "[...] no se procesan acá porque tenemos el problemita de la luz, tenemos el equipo, tenemos el químico encargado incluso del área, pero como no funciona el abasto energético, no es el suficiente para echar a andar los equipos de laboratorio" (Entrevista 3).

Es decir, que algún proyecto o centro que funcione específicamente por ser Ciudad Rural Sustentable no existe, este es el argumento para colgar de la Ciudad artificial de Santiago El Pinar una etiqueta que rece "Ciudad Rural Sustentable FRACASADO". Condición que puede no definirse por el santiaguero "reubicado", pero le consta las carencias que arrastra en la "Ciudad", es decir, el fracaso le es palpable con otro nombre.

Figura 3. Imágenes de la Ciudad Rural Sustentable "Santiago El Pinar": rostros de un fracaso.

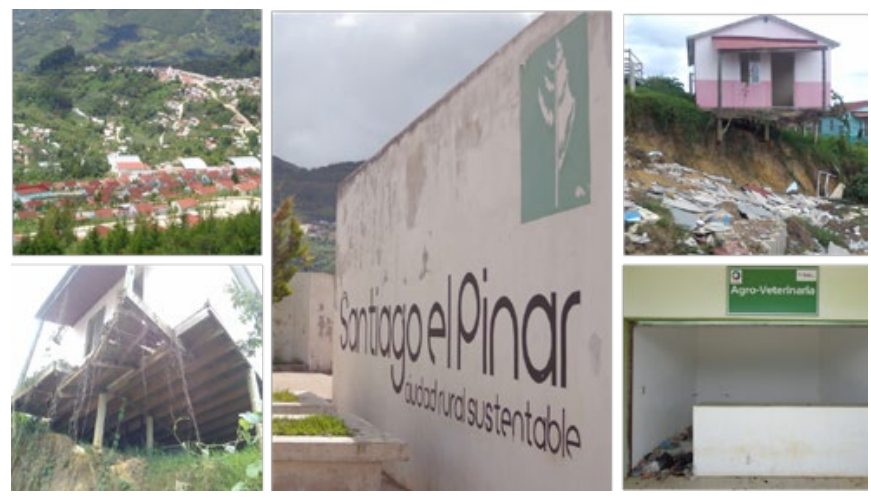

Fuente: Fotografías propias.

Diversas investigaciones vislumbraron mediante diversos enfoques de estudios de factibilidad el fracaso que se avecinaba a la CRS, condición que es "multifacético", va desde su localización geográfica hasta su estructura arquitectónica.

De las únicas ventajas de haber construido la CRS en las laderas del cerro y marcado por semejante pendiente, como menciona también Larsson, es que permite enfocar y encontrar un buen ángulo para la foto, bien como fondo el sol y el "mar azul", o apreciar lo extendido de las edificaciones desde las alturas de la Ciudad Rural tomando como buen panorama los paisajes del noreste, que según Larsson "señala un posición moral elevada" de la Ciudad (2012). - ¿A poco alguien se preocupó por la moral del santiaguero?-.

Sin embargo, es importante mencionar que el fracaso de la Ciudad Rural Sustentable no debe de entenderse desde el parámetro de las Políticas Públicas, sino desde la construcción teórica que le da origen, es decir, desde el sistema económico capitalista en su inesperada e histérica búsqueda de solución a su estado caótico, hecho que se convierte a su vez, en bases fundacionales para elaborar otras formas similares de asistencialismo.

II.- "Santiago El Pinar" fue una política de contrainsurgencia que también fracasó. Se interpuso la estrategia en el centro de los cuatro puntos cardinales, entre cuatro territorios rebeldes donde "el pueblo manda y el gobierno obedece”: San Andrés Sakamch'en de Los Pobres al Sur, San Juan de La Libertad al Norte, Magdalena de La Paz al Oriente y Oventic que luce en el Poniente, este último "corazón céntrico de los zapatistas delante del mundo", el Caracol II, el centro político zapatista más importante después de "La Realidad".
El objetivo gubernamental no era atender demandas añejas, pero tampoco era directamente desarticular "caracoles zapatistas" como menciona Wilson, fue parte de la contrainsurgencia sí, utilizando el Aparato Económico de la estrategia de Guerra de Baja intensidad (GBI) donde el objetivo fue debilitar a las bases zapatistas localizando un centro de distracción estratégico que fragmentara las comunidades en resistencia. Es decir, mediante la guerra económica de otorgar proyectos y apoyos asistencialistas directos con el fin de disminuir la presencia rebelde en las zonas de influencia.

Santiago El Pinar, es cierto, es de los municipios más desprotegidos en el país, según fuentes del IPCR (s/f) tiene el nivel medio en Índice de Desarrollo Humano (0.6387) y tiene el índice de marginación muy alto (2.2194). No obstante, no se encuentra asentado en una zona geográfica de "alto riesgo", pero le fue aplicado la misma estrategia que "Nuevo Juan del Grijalva", y entonces cuatro de sus comunidades fueron "reubicadas" hacia una zona de suicidio, hacia las laderas de un cerro que presenta alto riesgo de deslizamiento en tiempos de lluvia.

La estrategia fue mal calculada, millonarias inversiones para que brille los rastros de lo que fue la Ciudad Rural Sustentable donde viven no mayor de 16 familias aprovechando un tercio de terreno extra. La contrainsurgencia fracasó también, directamente no hubo influencia ni fragmentó el movimiento rebelde en el municipio y menos en la región, por el contrario, fortaleció la resistencia de las comunidades zapatistas.

III.- La Ciudad Rural Sustentable "Santiago El Pinar" refleja el estado caótico (crisis) del Estado capitalista mexicano como respuesta a la precipitada gestación y crecimiento acelerado de movimiento de masas y movimientos sociales con grados mayores de consolidación política y fortalecimiento de otros ya existentes. Voces levantadas contra el régimen que rechazan la putrefacta clase política que representa, y coadyuva en el fracaso de los planes estratégicos de contrainsurgencia y de apaciguamiento sobre territorio rebelde, como es la implementación misma de las Ciudades Rurales Sustentables y programas similares.

Camacho Velázquez identifica que las Ciudades Rurales Sustentables fueron una política exacta para justificar corrupción y despilfarro por parte de los niveles de gobierno, de la burocracia capitalista y de la clase política dominante en México (Entrevista 11). Que no solo son consideraciones válidas y acertadas, es justo mencionar que todo el paquete de la llamada política social y pública, ha sido precisamente para eso, para justificar y ocultar corrupción e impunidad, y la crisis que impera, lo que también ha repercutido en las diversas movilizaciones que ahora llevan el derrotero sólo al compás de las coyunturas como consecuencia.

En movimientos donde existe una agenda de lucha trazada y donde fracasa la mayoría de los intentos gubernamentales, se siembra el terror Estatal que se resume en el carácter represivo de éste sobre los movimientos y movilizaciones sociales. De este proceso se desencadena que el Estado está en constante cambio y transformación para implementar mejores políticas y más adecuadas para cada particularidad socio-geográfica (la agudización de la lucha de clases).

Si consideramos que el Estado está en constante transformación política no para atender las necesidades sociales, sino para controlarlos, entonces esa transformación significa crisis permanente (que se acumula) al no encontrar la forma adecuada de ejercer el poder contra los más, quienes también están en constante búsqueda de una forma más efectiva de resistencia ante la embestida Estatal. Una crisis que ya no es la esencia del sistema como era originariamente para generar riquezas, sino una en estado de descontrol que se vuelve contra sí misma y sin recetas de solución que antes diseñaba. 
Esto es resultado de una estructura de poder que implica que el Estado mexicano está sujeto de otros poderes de orden global, ese poder es el que llamamos el modo capitalista de producción, de acumulación y de explotación. A su vez, arroja resultados de especulación de las políticas elaboradas desde escritorios multilaterales, como son las recetas de la estrategia de Ciudades Rurales que se desprende desde Premios Novel de Economía, del Banco Mundial o de la misma Organización de las Naciones Unidas con la farsa que fueron los Objetivos de Desarrollo del Milenio de donde se sujeta una enorme cantidad de políticas asistencialistas.

IV.- Con el fracaso de las Ciudades Rurales Sustentables, teniendo a "Santiago El Pinar" como ejemplo inmediato, podemos reafirmar una parte de los diversos rostros y facetas de la multiplicidad de la crisis estructural del sistema y del Estado mexicano como resultado de la relación de poderes existentes, con una expresión definida en muchas políticas públicas de ámbito local, como fueron las propias Ciudades Rurales Sustentables.

Es decir, en los momentos en que la turbulencia sistémica, provocado ésta primeramente por el carácter violento, voraz y barbarie del capitalismo salvaje, lanzan políticas de reestructuración (de recuperación sistémica) en nombre del "progreso" y del "desarrollo". Una de las expresiones más desastrosas de esta turbulencia se materializa con la crisis económica que afecta a millones en el mundo con despidos laborales, hiperinflación descontrolada y generalizada, alza de las tasas de impuestos, deuda externa en niveles antes inimaginables (ahora llamado "compromiso financiero" del contribuyente), caída de los salarios mínimos, restricciones a los derechos de seguridad social, miseria, hambruna, entre otros eventos, crisis que no debe sus razones a catástrofes naturales como en el pasado siglo XIX, o de una sobreproducción como la que causó el "jueves negro" de aquel 1929 y todo lo que posterior al evento desencadenó.

Tiene que ver, por lo tanto, con la disputa de mercados y de la competencia neoliberal avalada y/o entablada por y entre firmas multinacionales etiquetadas de Fondo Monetario Internacional (FMI), Banco Mundial, Organización para la Cooperación y el Desarrollo Económico (OCDE), Banco Interamericano de Desarrollo (BID) y otras compañías parecidas. Inestabilidades macroeconómicas a nivel planetario que los zapatistas del EZLN reconocen como "catástrofe que se avecina".

Este círculo contradictorio del capitalismo, obliga al mismo a succionar al máximo todas las fuentes de riqueza, es decir, los recursos naturales, para no limitar la ininterrumpida lógica de acumulación. Para ello, re-define políticas para ocultar primero la catástrofe, y luego para imponer nuevas formas acumulativas mediante el ejercicio de las facultades que el sistema le ha conferido al Estado, como es la llamada financiarización, flujo desmedido de recursos (por lo regular de préstamos externos) para financiar proyectos y políticas sociales descontextualizados basados en la especulación.

Las Ciudades Rurales Sustentables son el ejemplo claro de obras especulativas, una forma de maquillar una "catástrofe", de justificar desplazamientos forzados y por lo tanto, de despojos y formas de coartar el proceso organizativo de las rebeliones: crisis causadas por la misma "catástrofe", es decir, cuando adquiere su condición de contrainsurgencia.

Las Ciudades Rurales son una expresión de que en éste tránsito turbulento, la crisis acumulada del sistema, no necesariamente se tiene que formular políticas en pro de incrementar la producción y la productividad, o la explotación de los recursos y de la fuerza de trabajo, sino la explotación de la inconciencia y de la ignorancia que el mismo sistema reparte mediante proyectos asistencialistas y la privación de derechos fundamentales para taponear las goteras de la sombra capitalista y de la inestabilidad macroeconómica nacional. Esas son, según este modo de análisis, otra faceta de la crisis y su expresión en las CRS. Es decir, las CRS fueron métodos de transformación e intentos de recuperación de la crisis actual del sistema social y económico capitalista en México. Porque como dice Rodríguez:

No estamos viviendo una crisis coyuntural del modelo de acumulación o del sistema político de partidos. Lo que hoy se expresa es la crisis del dominio. Lo que hoy está en cuestión es la relación mando-obediencia. Vivimos una crisis del sistema de dominación. (2010: 61)

Sin embargo, es importante entender que cuando hablamos de una crisis del sistema económico, puede dirigirse a distintas posiciones de interpretación. En este trabajo se considera que la crisis del capitalismo no está reflejada en el comienzo de un nuevo sistema económico-social diferente a éste, (que bien pudiera ser el paso al socialismo), pues implicaría la desarticulación y colapso de las relaciones sociales de producción actual (relación de mandoobediencia; explotadores-explotados) que dan base al modo capitalista de acumulación, hecho que se encuentra todavía lejos de las posibilidades actuales.

Por el contrario, hace referencia a un proceso de transformación social y económico caracterizado por la abundancia de movimientos sociales; es decir, un proceso de transformación amplio basado en las múltiples prácticas consecuentes de luchas y movimientos. John Holloway señala que "Nosotros somos la crisis del capitalismo [...] es nuestra dignidad y nuestro pensamiento crítico la crisis del capitalismo [...] somos el valor de uso contra el valor de cambio" (2015: s/p, en Seminario Internacional el Pensamiento Crítico frente a la Hidra capitalista; inédito)

La crisis del sistema económico capitalista que surge a raíz de las modernas guerras contra territorios no sólo es en México ni América Latina, en todas las geografías se refleja la catástrofe multidimensional, la estructura caótica del edificio sistémico, incitado fundamentalmente por las contradicciones en la lógica de acumulación, en la que el valor de cambio se impone sobre el valor de uso, y tanto la fuerza de trabajo socialmente necesaria como la satisfacción de las primeras necesidades, quedan en segundo plano para dar mayor prioridad a la acumulación del plusvalor (trabajo no remunerado).

Las Ciudades Rurales Sustentables como secuela de la guerra de baja intensidad, la guerra psicológica que no busca sólo la ruptura de pueblos y comunidades, sino la aniquilación total para imponer los intereses del dinero es el reflejo de la degradación de las prácticas y gradual deserción de la ideología capitalista en tanto se implementan para ocultar la crisis e inestabilidad que ello implica. Y es reflejo de la lucha de clases y de la lucha de entre abajos (precipitada por el conjunto de las políticas gubernamentales) en tanto son prácticas bajo la lógica de contrainsurgencia planeada desde el sistema y ejecutada por el Estado mexicano; ambos hechos se correlacionan, y cada uno adquiere sentido en el otro.

Todo este complejo engranaje, vaivén de la Ciudad Rural Sustentable, fue posible mediante el uso y abuso de los recursos del erario público y de las inversiones extranjeras directas que se presentan como deuda externa. Existen muchas divergencias sobre las aproximaciones a las cifras canalizadas para el proyecto de CRS establecidas en todo el territorio estatal, por eso, todas las que se manejan son sólo cálculos aproximados.

Con referencia a las cifras manejadas para el proyecto de "Santiago El Pinar" hay también muchas incongruencias y números que en las sumas y restas quedan sin valor. En el Cuarto y Quinto 
Informe de Gobierno de 2010 y 2011 respectivamente, se dan a conocer las cifras más acertadas y mayor difundidas, señalan:

Para la edificación de la ciudad rural sustentable de Santiago El Pinar, autorizamos 394 millones 460 mil pesos, provenientes del gobierno federal; al 30 de septiembre el proceso constructivo presenta un avance de 55.74\%. (Cuarto Informe de Gobierno, 2010: 82)

[...] en coordinación con el gobierno federal destinamos más de 394 millones de pesos para cambiar radicalmente el rostro de la marginación y el atraso de sus habitantes [de Santiago El Pinar]. (Quinto Informe de Gobierno, 2011: 89)

No obstante, en los Informes Regionales correspondientes a cada Informe Gubernamental, se pueden clasificar las inversiones por sector, por servicios e infraestructura, o por proyectos. En el Quinto Informe hace referencia sobre la infraestructura urbana que se estaba edificando en la Ciudad Rural Sustentable, donde se pueden clasificar la educativa, de salud, religiosa, económico-social y de gobierno, es decir, los elementos que integran los Componentes o Subsistemas que se construyeron.

Así, tomando en cuenta fundamentalmente los datos del Sexto Informe de Gobierno de 2012, la suma arroja un total de 400 millones 006 mil 080 pesos, dato que difiere poco con los 394 millones 460 mil anunciado en el Cuarto y Quinto Informe de Gobierno específicamente para la Ciudad Rural Sustentable "Santiago El Pinar"; de tal forma que si se restara las inversiones de reparación ejercidas en el 2012 después de la inauguración, que ya no formaron parte de la inversión inicial para la CRS, arroja un resultado de 389 millones 776 mil 865 pesos (ver cuadro 1).

Libert (2012) y Larsson (2012) hacen el cálculo sobre la inversión por habitante realizadas en Nuevo Juan del Grijalva y "Santiago El Pinar" respectivamente para buscar la equivalencia del total invertido fraccionado en el número de beneficiarios o habitantes.

Es decir, para este caso, si tomamos en cuenta a las 116 viviendas de la Ciudad Rural para dividir entre éstas el monto final invertido hasta 2012 que fue de 400 millones 006 mil 080 pesos en el Proyecto, da como resultado 3 millones 448 mil 328 pesos para cada hogar, $\mathrm{y}-$ ¿si comparamos las ventajas de semejante suma a con las condiciones actuales de vida de las 16 familias sobrevivientes de la CRS? -.

Son estas las grandes contradicciones de origen y resultados de un programa gubernamental a las que se deben replantear, donde también halla razón la tesis que supone la existencia de objetivos contrainsurgentes financiados con recursos salidos del erario público.

Pickard (2012) señalaba en "El ABC de las Ciudades Rurales Sustentables" la imposibilidad de rastrear los orígenes de la inversión ejercida en este programa gubernamental en las seis Ciudades Fantasma que han sido inauguradas en Chiapas. La inversión materializada en las CRS nunca ha sido transparente, pero las aproximaciones revelan un monto abrumadoramente elevado y desfasado de los objetivos para los que fueron prestados, sustraídos, acumulados, robados, ejercidos, canalizados, - o el calificativo que usted le quiera adjudicar-.

Es equivalente o mayor a la moda de calificar ahora cualquier cantidad en cualquier gobierno y de cualquier color, de cifra histórica.

Cuadro 1. Inversiones por infraestructura en la CRS "Santiago El Pinar".

\begin{tabular}{|c|c|c|}
\hline Proyecto & Organismo ejecutor & Presupuesto invertido $(\$ \mathrm{mx})$ \\
\hline Estudio de la CRS "Santiago El Pinar" & $\begin{array}{l}\text { Secretaria de Infraestructura } \\
\text { (Seinfra) }\end{array}$ & 580,000 \\
\hline Parque recreativo en Barrio Ninamhó para la CRS & Seinfra & $1,190,000$ \\
\hline $\begin{array}{c}\text { Construcción de la Red Principal de Drenaje para las Ciudad Rural } \\
\text { Sustentable }\end{array}$ & Seinfra & $5,950,000$ \\
\hline Pilotes de concreto para viviendas de la CRS & Seinfra & $3,066,722.64$ \\
\hline Planta de Tratamiento de Aguas Residuales & Seinfra & $1,076,011.70$ \\
\hline Pavimentación de calle en la CRS & Seinfra & $1,191,000$ \\
\hline Corte de Plataforma para Nave Ensambladora & Seinfra & $1,112,675.69$ \\
\hline Estudio y Proyecto Ejecutivo para el Sistema de Saneamiento & Seinfra & $700,000.00$ \\
\hline Instalación Eléctrica Media Tensión para Nave Ensambladora & Seinfra & $2,154,596.31$ \\
\hline Plataformas Para Planta Ensambladora & Seinfra & $3,279,250.4$ \\
\hline $\begin{array}{l}\text { Programa de Desarrollo Urbano del Centro de Población y Ante- } \\
\text { proyecto de Diseño en la CRS }\end{array}$ & Seinfra & $700,000.00$ \\
\hline Proyecto Integral de la Ciudad Rural Sustentable de Santiago El Pinar & Seinfra & $346,602,368.32$ \\
\hline Suministro y Colocación de Pasto en el Exterior de Ensambladora & Seinfra & $142,000.00$ \\
\hline Construcción de Obras Complementarias a la Vivienda & IPCR & $10,500,000.20$ \\
\hline $\begin{array}{c}\text { Acondicionamiento de Terrenos, Accesos y Provisión de Servicios } \\
\text { para el Establecimiento de Proyectos Productivos }\end{array}$ & Seinfra & $3,897,761.10$ \\
\hline Aplanados y Pintura en Interiores de Viviendas Existentes & Seinfra & $14,598,963.00$ \\
\hline \multirow[t]{2}{*}{$\begin{array}{l}\text { Construcción de Bases para la Cimentación de Viviendas Prefabrica- } \\
\text { das en Sustitución de las Viviendas de Madera }\end{array}$} & Seinfra & $7,162,491.81$ \\
\hline & & Total: $400,006,080.07$ \\
\hline
\end{tabular}




\section{A MODO DE CONCLUSIÓN}

... O sea que estábamos mejor cuando estábamos peor.

(Pickard, 2012)

En el "Discurso del método”, Descartes señala: "No aceptar nunca cosa alguna como verdadera que no la conociese evidentemente como tal” (1968). Para la Ciudad Rural Sustentable "Santiago El Pinar" hay los argumentos y razones suficientes para considerar que su fracaso es irrefutable.

Es evidente que mucho se ha discutido en las últimas décadas para seguir manteniendo el rating teórico de una moda de escritorio llamada "desarrollo", una moda que ha sido motivo y cuartada para que día a día en cualquier geografía se (re)tracen políticas en todo espectro de gobierno.

Desde la concepción de los modelos económicos basados en la lógica de acumulación capitalista, toda política social han sido los mismos, pese a la aparente transición de poderes en cada periodo de gobierno.

En México, desde la década de los 80 cuando adoptaron el modelo neoliberal como método de mero crecimiento, las políticas sexenales fueron y siguen siendo variados pero regidos bajo la misma lógica de ejercicio, esquivando los modos históricos de vida, las redes de autonomías comunitarias y la ética y principios sociales propios en los territorios donde van desarticulando lo que en otros términos llaman "tejido social".

Pero han sido casi mismos los rotundos fracasos que en su aplicación enfrentan debido fundamentalmente por su excedido contenido asistencialista basados en el método excluyente de planeación, cada vez menos participativos, que son parte, de hecho, de las reglas que el capitalismo impone.

La perspectiva de la Ciudad Rural Sustentable no podría ser entendida cabal si no se desenreda primero el lío que la política partidista ha tejido, es decir, la estructura de poderes. Condición que determinó el rumbo que siguió los pasos del "elefante blanco": el fracaso, -puede escribirse con mayúsculas y en negrita-, aunque ahora se pretenda que ese elefante se vuelva pasajero, que el espectador o víctima no tenga memoria, o cuando menos hacerle creer que el de otro color no se encargará de montar otro circo con un "elefante" similar.

Domingo Fernando, un habitante y actor político en Santiago El Pinar, señala:

"[...] aquí ya no hay beneficios, nada que te acuerdes de la Ciudad Rural, de plano. [- ¿Cree usted que todavía puede haber una mejora para el municipio a través de la Ciudad Rural?-] De la Ciudad Rural se puede valer si se reactiva los proyectos, pero es en segundo término. [...] un proyecto parecido pues con este antecedente la gente ya lo pensaría dos veces porque vio que la primera ciudad o el primer apoyo no funcionó, se tendría que ver como vendría esa ciudad, proyecto o apoyo para aceptarlo o rechazarlo" (Entrevista 15).

Que haya un futuro económico de la Ciudad Rural Sustentable "Santiago El Pinar" es improbable, por no decir imposible. Como menciona Domingo Fernando, de la cita anterior, efectivamente pueden reactivarse todos los proyectos productivos implícitos que ahora se encuentran varados; sin embargo, su posible reactivación tiene que ser independiente del funcionamiento de la Ciudad Rural como tal, porque ésta no reúne las condiciones físicas para ser habitada y tampoco presenta condiciones culturales para acoger a las familias santiagueras. Me refiero a que las viviendas no son las adecuadas para ser habitadas por familias con características diversas y tradiciones milenarias de antaño que se esfuma en los modos de vida dentro de la Ciudad Rural (el Derecho a la libre determinación).
Por lo tanto, la CRS no podrá ser un centro de población como cualquier otra comunidad, caben posibilidades de quedar totalmente abandonada si no se atienden las necesidades más urgentes y básicas como el agua potable y el drenaje sanitario en los próximos meses. Mientras que el remoto ejercicio de los proyectos productivos de la Ciudad Rural, será como cualquier otro proyecto cuyos beneficiarios, vivan como siempre lo han hecho, en sus comunidades de origen, hecho que significa que la productividad y las rentas generadas no serán para la "sostenibilidad" ni la "sustentabilidad" de la Ciudad Rural, sino para el sustento de las familias beneficiadas viviendo en sus localidades respectivas.

Hasta ahora, el (dis)funcionamiento de la Ciudad Rural tiene que ver con el sistema de políticas sociales vigentes en el país, pero la trayectoria en el caso de "Santiago El Pinar" ha tenido mucho que ver con la militancia que los involucrados han fijado, y con la militancia o el color partidista de los administradores en turno.

Es cierto que la dispersión ejerce una intervención negativa sobre el desarrollo económico-social de las poblaciones, sin mencionar que la alta concentración también puede significar hacinamiento como sucede ahora en las grandes urbes (De León et al, 2010). Pero suponiendo que la concentración de la dispersión es una medida válida, la política más estratégica y por lo tanto efectiva de desarrollo de las poblaciones que han de ser concentradas, es aquella que los propios pueblos y comunidades determinen sin afectar sus valores e identidades.

Uno de los mayores problemas que encontré en Santiago El Pinar, -quizá suene más como recomendaciones, como en otros estudios se anexan-, es la alta o total dependencia de la sociedad hacia los programas gubernamentales asistencialistas. La gente ha sido malacostumbrada a vivir permanentemente con apoyos en especie, en proyectos productivos, o en efectivo en el caso de las mujeres y de los adultos mayores.

Cuando un proyecto asistencialista termina, se reforma (Progresa-Oportunidades-Prospera) o fracasa, como es la Ciudad Rural Sustentable, o alguien defrauda y hace mal uso de esos recursos y nadie se empeña por recuperarlos (como el supuesto desvío de recursos para viviendas hecho por el Presidente Municipal de Santiago El Pinar), es cuando la gente empieza a palpar que su pobreza no es una decisión divina, la presión sobre su aparente bienestar económico permite percibir que alguien es culpable de su pobreza, pero poco sabe sobre ello, y empieza a creer que se debe a la ausencia de los apoyos del gobierno de los que estaba acostumbrado.

Si bien, no está en discusión el papel fundamental de toda forma de Estado sobre el bienestar social que debe garantizar mediante el ejercicio democrático del recurso fiscal o de la Inversión Extranjera Directa (IED) o deuda pública que pasa a clasificarse como ingresos, pero ese papel no debe de recaer en políticas asistencialistas que hace a la gente menos productiva y más dependiente de recursos externos, volátiles en el mercado cambiario de las decisiones gubernamentales, es decir, dineros fugaces que se retiran cuando los intereses o las condiciones políticas así convengan.

Por el contrario, el Estado tiene que generar políticas económicas más incluyentes y menos restrictivas con respecto a los derechos sociales, es necesaria la generación de fuentes de empleo con adecuados estudios de factibilidad acorde a las condiciones sociogeográficas de las unidades económicas particulares, e identificar los potenciales humanos y naturales de dicha unidad (las ventajas comparativas o competitivas).

Reconozco que con estas palabras el escrito suena muy reformista y progresista, pero se hace válida por una razón: el Estado está obligado ahora de replantear sus políticas sociales de elevado carácter asistencialista que ha profundizado la línea divisora y el abismo que separa la pobreza con el bienestar social, con el "Buen 
Vivir”, mientras que también es el motor y/o la condición clave que determina cuántas voces más de reclamo deben retumbar "su mundo”, el de ellos, el de arriba, para que en la política actual se dé una transición total, o en definitiva la muerte de esta política para que renazca esta otra que va "resurgiendo".

Por ultimo podemos retomar las preguntas que Pickard (2012) plantea cuando Manuel Velasco (Gobernador actual de Chiapas) aún estaba en el repunte de las estadísticas electorales, señala:

[...] ¿Tendrá las mismas prioridades que Juan Sabines y seguirá subsidiando los proyectos y las (pocas) fuentes de trabajo en las Ciudades Rurales? O ¿Impulsará sus propios megaproyectos para su lucimiento personal, dejando salpicado el paisaje chiapaneco de estos elefantes blancos que son las Ciudades Rurales "Sustentables"? (Pickard, 2012: 34)

Se ha respondido en parte la primera de las preguntas, evidenciando que desde la transición de la gubernatura chiapaneca se abandonaron los proyectos de las Ciudades Rurales en las seis que al menos en territorio chiapaneco subsistían.

Y aquí radica la necesidad mayor de hacer praxis la palabra y la teoría que la realidad demanda, es decir, de asumirlas de forma transformadora, porque "ni sola la teoría, ni sola la práctica" dicen los zapatistas.

\section{Agradecimientos}

A las mujeres y hombre de Santiago El Pinar quienes me acogieron en diversos momentos durante mi trabajo de investigación. A la Facultad de Ciencias Sociales de la Universidad Autónoma de Chiapas. A los lectores de la Tesis de Licenciatura de donde se sustrajo el contenido principal de este Artículo: a los maestr@s Fernando Hernández, Martín Manuel, Guillermo Montoya mi Director de Tesis; a los maestros y colegas: compañeros Eliezer Fernando y Antoine Libert.

Quedo sobre todo agradecido con la Dra. Alicia Ferreira Gonçalves de la Universidad Federal de Paraíba, Brasil, quien me invitó a escribir y publicar este artículo y por sus contribuciones y críticas al manuscrito, así como la traducción al portugués del resumen.

\section{REFERENCIAS}

Arnold, A.; Carter, L.; Hill, M.; Amber J., Amber; McCormick, M.; Sakamoto, K.; Teerasupaluck, T.; Usmani, R.; Vaporis, M.; Witwer, M. 2011. A rights-based analysis of the Sustainable Rural Cities Program: the case of Santiago El Pinar, Department of City and Regional Planning. New York: Cornell University.

Burguete, A.; Torres, J. y Álvarez, F.R. 2006. Santiago el Pinare, Sk'oplal ya'yejal jteklum. Tuxtla Gutiérrez, Chiapas: Consejo Estatal para la Cultura y las Artes de Chiapas.

Dávila, E.; Kessel, G. y Levy, S. 2002. El sur también existe: un ensayo sobre el desarrollo regional de México. Economía Mexicana, vol. XI N². pp. 205-260.

De león, K.; Ferguson, N.; Ferry, D.; García, A.; García, G.; Hafeez, M.; Ham, C.; Hay, T.; Romo, M.; Seiler, G.; Shaikh, S.; Shum, C.; Tagawa, T.; Tong, M. 2010. Analyzing the Sustainable Rural Cities Program, Department of City and Regional Planning. New York: Cornell University

Gobierno del Estado. 2010. Cuarto Informe de Gobierno. Gobierno del Estado de Chiapas, Tuxtla Gutiérrez, Chiapas, México.
Gobierno del Estado 2011. Quinto Informe de Gobierno. Gobierno del Estado de Chiapas, Tuxtla Gutiérrez, Chiapas, México.

Gobierno del Estado 2012. Sexto Informe de Gobierno. Gobierno del Estado de Chiapas, Tuxtla Gutiérrez, Chiapas, México.

Gómez, E. 2015. La Ciudad Rural Sustentable "Santiago El Pinar": una realidad socioeconómica. Referencias de la crisis estructural del Estado. San Cristóbal de Las Casas, Chiapas: Tesis de la Facultad de Ciencias Sociales de la Universidad Autónoma de Chiapas (Inédito).

INEGI 2010. Instituto Nacional de Estadística, Geografía e Informática. Censo de Población y Vivienda 2010.

IPCR, Instituto de Población y Ciudades Rurales (s/f-a). http:// www.ciudadesrurales.chiapas.gob.mx. (Consultado el 25 de Mayo de 2014).

IPCR, Instituto de Población y Ciudades Rurales (s/f-b). Diagnóstico. http://www.ciudadesrurales.chiapas.gob.mx/ diagnostico. (Consultado el 25 de Mayo de 2014).

Klein, N. 2007. La doctrina del Shock: el auge del capitalismo del desastre. México: Paidos.

Larsson, M. 2012. El brillo de la imagen: la disputa por la Ciudad Rural Sustentable en Santiago El Pinar. San Cristóbal de Las Casas, Chiapas: Tesis del Centro de Investigaciones y Estudios Superiores en Antropología Social (CIESAS).

Libert, A. 2012. Dialógicas del territorio en Chiapas: un análisis sistémico-complejo del proyecto Mesoamérica. San Cristóbal de Las Casas: Tesis de la Universidad Autónoma de Chapingo.

Marx, C. \& Engels, F. 1985. Manifiesto del Partido Comunista. Moscú: Progreso.

Pickard, M. 2012. El ABC de las Ciudades Rurales Sustentables. http: / / radiozapatista.org/?p=5581. (Consultado el 15 de Diciembre de 2013).

RED por la Paz y CAIK. 2012. De la tierra al asfalto. Informe de la misión civil de observación de la Red por la Paz Chiapas y CAIK al programa Ciudades Rurales Sustentables. San Cristóbal de Las Casas: Fray Bartolomé de Las Casas, A.C.

Rodríguez, S. 2010. La Crisis del Poder y Nosotros. México D.F.: Ediciones Rebeldía.

Wallerstein, I. 2005. La crisis estructural de Capitalismo. Centro de Estudios, Información y Documentación "Immanuel Wallerstein”, México: Contrahistorias.

Wilson, J. 2009. Abstract space and the Plan Puebla Panama: a Lefebvrean critique of regional development in southern Mexico. Tesis Doctoral, Manchester: Universidad de Manchester.

Entrevista 3. Personal del Centro de Salud con Servicios Ampliados (CSSA). Realizada el 11 de Junio de 2014 en la Ciudad Rural Sustentable "Santiago El Pinar".

Entrevista 11. Dra. Dolores Camacho Velázquez del PROIMSEUNAM. Realizada el 19 de Febrero de 2015 en San Cristóbal de Las Casas, Chiapas.

Entrevista 15. Domingo Fernando Rodríguez Gómez, habitante de la cabecera municipal de Santiago El Pinar y propietario de un lote de la Ciudad Rural Sustentable. Realizada el 18 de Enero de 2015 en Santiago El Pinar, Chiapas. 